\title{
Entrevista al Dr. Alfredo Bruno Bologna sobre el estado de la disciplina de las Relaciones Internacionales en Argentina
}

\author{
Melisa Deciancio*
}

Esta entrevista forma parte de la investigación para mi tesis doctoral que buscó rastrear la historia del campo de las Relaciones Internacionales (RI) argentinas. En este marco y en ocasión de la Conferencia FLACSO-ISA, realizada en Buenos Aires en julio de 2014, tuve la grata oportunidad de entrevistar al Profesor Dr. Alfredo Bruno Bologna como uno de los referentes de la disciplina en el país. El objetivo fue poder indagar sobre su trayectoria personal en el marco del devenir histórico de la disciplina y del desarrollo de una de las principales instituciones de referencia en RI en el país como la Universidad Nacional de Rosario (UNR).

Heredero de la tradición de Juan Carlos Puig y referente de la Facultad de Ciencia Política y Relaciones Internacionales de la UNR, el Profesor Bologna egresó en 1966 como Licenciado en Ciencias Políticas y Diplomáticas de la Facultad de Ciencias Económicas, Comerciales y Políticas, que en aquellos momentos dependía de la Universidad Nacional del Litoral (UNL). Se doctoró en Ciencias Políticas y Diplomáticas en 1975 en la Facultad de Ciencia Política y Relaciones Internacionales de la Universidad Nacional de Rosario, con su tesis sobre "América Latina y los Estados Unidos a través de la Comisión Especial de Coordinación Latinoamericana. CECLA. 1969-1973”, bajo la dirección del Dr. Juan Carlos Puig.

Su trayectoria académica hizo que fuera una entrevista obligada para reconstruir la historia del campo de las RI y poder destacar el lugar pionero que la disciplina ha encontrado en la Universidad Nacional del Litoral primero y la Universidad Nacional de Rosario después. La historia de la disciplina atravesó uno de sus puntos más relevantes en su - aún incipiente proceso de autonomización e institucionalización, con la creación de la Licenciatura y el Doctorado en Estudios Consulares y Diplomáticos en la UNL en el año 1923. En consonancia con lo sucedido durante los años conservadores en Buenos Aires, los intelectuales-diplomáticos formados en Derecho en la UNL, provenían de las más destacadas familias de la provincia de Santa Fe, especialmente de la ciudad de Rosario, desde donde se esbozaron los cimientos de la disciplina con un gran contenido autonomista. Tanto la Licenciatura como el Doctorado en Diplomacia de la UNL fueron los antecesores naturales de la actual carrera y doctorado en Relaciones Internacionales de la UNR.

Los aportes realizados desde la Diplomacia y las carreras de formación en la UNL primero, y en la UNR después, marcaron el rumbo del proceso de autonomización de la disciplina. Esto se debió a que se generó en Rosario un colectivo especializado en RI que persiste hasta nuestros días y que tuvo un rol fundamental en el desarrollo de la disciplina en las aulas de las universidades a nivel nacional. Siendo los primeros y más especializados profesionales en el campo de las RI, participaron como docentes y referentes en la creación de gran parte de las carreras y maestrías de RI en universidades nacionales de otras ciudades como La Plata, Córdoba, Mendoza, La Rioja y Villa María, entre otras. Además es desde Rosario que se desarrolló en ese colectivo una de las teorías más relevantes para el análisis de la política exterior argentina y de los países periféricos, la teoría de la autonomía de Juan Carlos Puig (Míguez, 2010; 2013; Simonoff, 2012; Corigliano, 2006; Bologna, 2008).

\footnotetext{
* Doctora en Ciencias Sociales, FLACSO/Argentina. Magíster en Relaciones y Negociaciones Internacionales, FLACSO/Argentina y Universidad de San Andrés. Licenciada en Ciencia Política, Universidad de Buenos Aires. Becaria Pos-Doctoral del CONICET. Actualmente es la Coordinadora Académica de la Maestría en Relaciones Internacionales de FLACSO/Argentina. Correo electrónico: mdeciancio@flacso.org.ar
} 


\section{- ¿De qué manera ingresa al campo de las RI?}

- Por Derecho Internacional Público en la cátedra de Juan Carlos Puig. Luego tuve una beca en Brasil, en la PUC (Pontifícia Universidade Católica) en Río de Janeiro, que tenía una escuela de Sociología y Política donde había profesores de Francia y otros países. Esa experiencia me abrió mucho la cabeza para salir del Derecho Internacional y complementarlo con lo que sucedía en la práctica de las RI. Un ejemplo de la preeminencia del Derecho Internacional Público fue la creación de la Asociación Argentina de Derecho Internacional (AADI), de la cual soy uno de los fundadores y donde fui varias veces Director de la Sección de RI. Dentro de la AADI se crearon varias secciones: Derecho Internacional Público, Derecho Internacional Privado, que la creó Juan Carlos Puig, Derecho de la Integración y Relaciones Internacionales.

- ¿Qué temas, personas, instituciones influyeron en ello?

- Puig es uno de los precursores, porque a pesar de ser abogado especialista en Derecho Internacional, incursionaba en RI. Y a veces tuvimos disputas porque él escribía artículos que yo leía y algunos no me gustaban. Cuando sí me gustaban me decía por qué el otro no le gustó? Y yo le respondía que eran muy buenos artículos de Derecho Internacional pero no de RI. Entonces conversábamos las distintas maneras de enfocar el tema. Un profesor de Francia que se llamaba Robert Bosch había escrito varias cosas sobre sociología de las RI muy interesantes y empecé a buscar en todo el mundo libros sobre Sociología de las RI y temas relacionados. Bosch me hizo cambiar bastante la perspectiva, es decir, ver que en RI hay otros actores que a veces son tan relevantes en el mundo como los Estados. Así comencé a leer y conectarme con Raymond Aaron, quien me enviaba cosas personalmente. Me escribí con (Stanley) Hoffman, pero cuando era "el Hoffman europeo", no el Hoffman norteamericano vendido al imperio yankee. Cuando estaba en el Centro de Estudios Europeos intercambiaba correspondencia con Hoffman y era excelente.

\section{— ¿Dónde está trabajando actualmente?}

- En la Universidad me jubilé como docente, en CONICET estoy jubilado y contratado ad honorem. Pero estoy dando clases de posgrado. Yo creé en la Universidad una Maestría en Integración y Cooperación Internacional en el año 1996 y fui su Director durante varios años. Después fui Decano de la Facultad, cuando dejé el Decanato, volví a la Maestría y ahora la Maestría la dirige Miryam Colacrai. Allí estoy dando clase en una asignatura que se llama Relaciones Internacionales Contemporáneas (como el libro de Hoffman), que es una materia niveladora, introductoria a la problemática mundial, muy útil para aquellos ingresantes a la Maestría provenientes de distintas disciplinas.

- ¿En qué consiste el campo de las RI? ¿Podemos decir que existe un campo de las RI en Argentina?

- Yo creo que sí. Tengo algunos trabajos de la década de los '60 sobre cómo empezaron las RI con algunos autores de Grecia, autores de la política de poder también de los '60 en Gran Bretaña y del Derecho Internacional también. En la Academia de Derecho Internacional de La Haya algunos internacionalistas empezaron a hablar de RI. En estos momentos ya no hay duda tanto en el país como en el extranjero que las RI es una disciplina autónoma. En nuestra Facultad hubo muchas luchas intestinas por separar Ciencia Política de RI. Yo he estado de presidente de algunas reuniones muy complejas hasta que se llegó al actual plan de estudios de nuestra Facultad, que son 3 años comunes y 2 años separados para Ciencia Política por un lado y RI por el otro. De cualquier manera, la Facultad se llama de Ciencia Política y RI. Eso lo dejamos siempre presente y el poder de la Facultad siempre vino por RI, porque la carrera tiene una larga tradición que empezó con Derecho Consular y Derecho Diplomático. Esto se debió a que el puerto de Rosario era muy importante en esos primeros años del Siglo XX, así 
que el nudo fuerte de nuestra Facultad era RI, no Ciencia Política. Con los años después se agregó Comunicación Social y Trabajo Social. Y de esas cuatro carreras cuando era Decano trabajamos para crear cuatro Doctorados, los cuales están funcionando muy bien. Pero el núcleo duro de la Facultad era RI, por la tradición que venía de hacía mucho tiempo atrás.

- Relacionado a esta tradición que tiene Rosario como particularidad y la creación de la Carrera Consular a mediados del $20 .$. Antes de eso había habido un intento por crear una Carrera Consular en la Facultad de Derecho y Ciencias Sociales de la UBA, entre 1907-1908, pero eso se cerró y se pasó a Rosario. Quería saber el perfil particular que imprimió Rosario a la manera de estudiar y pensar lo internacional.

- El 19 puede tomarse como punto de partida. En la época de la diplomacia, era una de las pocas carreras donde se estudiaba Diplomacia, hasta que en 1963 se creó el Instituto del Servicio Exterior de la Nación (ISEN). Nosotros no nos opusimos a la creación del ISEN, pero habíamos propuesto que queríamos tener un porcentaje para que los egresados nuestros ingresaran directamente a la Escuela del Servicio Exterior. Así que hicimos manifestaciones públicas en Buenos Aires, cortamos la calle de manera escandalosa frente al Congreso, en Callao y Rivadavia. Algunos fuimos presos y mientras cortábamos la calle hacíamos contacto con los congresistas para que nos sacaran de la cárcel y poder volver a Rosario. Eso fue en el año 1964, en la época de Zabala Ortíz. Yo lo conocía bien por la Resolución 2065 de Malvinas, por la reunión del CECLA en Alta Gracia y otras cuestiones, pero teníamos esa disputa con él y no logramos convencerlo. Porque en esa época en Argentina en el único lugar que se estudiaba Diplomacia era en Rosario, quisimos defender eso, pero no lo logramos. La otra facultad pública en esa época era la de Mendoza, donde se estudiaba Ciencia Política con algunas materias de Derecho Consular.

- El hecho de que la carrera se haya desarrollado en Rosario le imprime una particularidad, de hecho, su creación se da casi en simultáneo con la creación de la primera cátedra del mundo, la Cátedra Woodrow Wilson, en 1919 en Aberyswyth.

- Pero lo que había en Rosario no eran RI, era Derecho Consular. Las RI llegan a la Facultad con la reforma del plan de estudios del año 1954 cuando se creó la Carrera de Ciencia Política y RI.

\section{— ¿Cómo ve el estado actual de la disciplina?}

- A mí me parece bárbaro. Porque si bien a nivel de grado no he notado gran avance, salvo en la Universidad de acá que se creó la carrera de Ciencia Política con especialización en RI, sí veo mucho avance en posgrados, fundamentalmente en Maestrías y, últimamente en los Doctorados, sobre todo porque el CONICET invirtió mucho en crear becas doctorales para los investigadores de nuestro país. Lo que quiero decir con esto es que se creó una Maestría en RI en La Plata, que hoy está a cargo de (Norberto) Consani, pero la mitad o casi la totalidad de los profesores eran de Rosario. De hecho el año pasado (2013) nos dieron un reconocimiento en La Plata por eso. Después (Francisco) Delich, cuando era rector de la Universidad Nacional de Córdoba creó una Maestría en RI, que ahora dirige Carlos Juárez Centeno, y ahí también empezamos a dar clases nosotros. ¡No éramos los mejores pero éramos los que estábamos! Por ejemplo, Carlos Juárez Centeno fue a la Universidad de La Rioja y no había Maestría, entonces les propone crear una Maestría en RI, así que fuimos a La Rioja a dar RI; fue a la Universidad de Villa María y no había Maestría, así que creó una Maestría en RI en Villa María, y así empezamos a recorrer nosotros todo el país dando clases. Yo fui dejando a los discípulos dentro del CERIR (Centro de Estudios de Relaciones Internacionales de Rosario) para dar un poco de espacio a las generaciones posteriores. También fue importante la SAAP, cuando se hizo el primer congreso en Huerta Grande en 1993 y nosotros manejábamos el área de RI, proponíamos temas, 
agenda, todo. Esto quiere decir que tanto desde el Derecho Internacional Público a través de la AADI, como en la SAAP desde el primer congreso, junto con otra gente, estuve a cargo del área de RI y ya para los otros congresos fui dejando a otros discípulos. Había distintas aristas donde podíamos intervenir. Ahora yo creo que ya pasó ese momento porque hay especialistas o doctores en RI diseminados por todo el país.

— ¿Cuál es su percepción de la relación entre académicos/desarrollo académico y el contexto socio-político del país?

- Yo creo que durante el gobierno de (Raúl) Alfonsín, después de la dictadura, hubo una apertura en todo y me acuerdo que en el CONICET nombraron de presidente a (Carlos) Abeledo. Él propuso que todo grupo que estuviera constituido pidiera subsidios, ahí nos anotamos y empezamos a acceder a subsidios desde la época de Alfonsín hasta ahora. Con eso logramos que además del sueldo del CONICET los investigadores tuvieran subsidios para comprar libros, insumos, lo cual nos sirvió mucho. Lo que veo en la actualidad es que tal vez la Presidenta (Cristina Fernández) se queja de que hay pocas noticias internacionales pero la realidad es que las cuestiones y problemas nacionales tapan a los internacionales. Yo me acuerdo que antes vos leías La Nación y las primeras cuatro páginas eran de noticias internacionales, ahora apenas tiene una página y todo lo demás son noticias nacionales.

En cuanto a la Cancillería, es relevante destacar que una vez hubo una reunión entre funcionarios de Cancillería y académicos para discutir los temas de agenda. Hubo un desayuno de trabajo donde yo plantee la importancia del tema Malvinas, iporque no podía ser que hubiera sólo cuatro personas en la Cancillería estudiando Malvinas! Les dije: imagínense que algún día nos entregan Malvinas, ¿qué hacemos? No hay leyes, no hay jurisdicción, nada. También nos reconocieron en el ISEN y nos invitaron a dar clases, algo que ahora es común, de hecho Anabella Busso va a dar clases permanentemente y lleva a colegas de Rosario. También debatimos muy fuertemente con Escudé sobre esta cuestión.

\section{- Deben ser peleas interesantes esas...}

- Sí, una vez tuvimos un encuentro fuerte en Córdoba, con dos micrófonos y hablábamos a la vez, la gente estaba "chocha”. ¡Era una pelea a muerte! Él me estima y nos llevamos bien pero él propuso la independencia de las Islas Malvinas en un memorándum para Cancillería, cosa que no se les había ocurrido a los Malvinenses durante muchos años. Y cada vez que nos reunimos me dice: "¿vas a hablar de eso?", ¡pero salió en el diario Clarín! ¡Lo leyeron todos! ...

- ¿Cuáles fueron, a su entender, los orígenes de la disciplina y/o el pensamiento sobre lo internacional en el país?

- En Cancillería se daba en un momento Política Internacional, mi cátedra antes no se llamaba RI, se llamaba Política Internacional. Yo en todos los lugares trataba de cambiarle el nombre. Yo comencé a dictarla en 1974, cuando decidí armar un equipo de docentes e investigadores que se especializaran en diferentes áreas geográficas del mundo, que ya comenzaba a ser inabarcable.

Así que empecé a armar el equipo: Gladys Lechini para África, Miryam Colacrai, que al principio se ocupó de Irlanda del Norte, pero estaba el gobierno militar así que cambió por Chipre; y empecé a armar un grupo de gente en la cátedra y en base a eso surgió el CERIR, un poco financiado indirectamente por todos estos subsidios del CONICET.

- Si tuviera que marcar un punto de inflexión en la historia de la disciplina, ¿cuál sería?

- Durante el gobierno militar a mí me decían “¿cómo dabas clase?” Y yo daba clases de Política Internacional, porque de Argentina no se podía hablar. Durante el gobierno 
militar tuve un allanamiento en mi casa, encontraron una gran cantidad de libros pero no tuve inconveniente. Lo que sí en esa época yo me dedicaba a estudiar América Latina, y en el Consejo de Investigaciones de la Universidad vino un colega y me dijo “¿por qué no cambias de tema?” y ahí por cuestiones de seguridad tomé Malvinas, no me iba a imaginar nunca que después iba a venir lo de la guerra y todo lo que siguió. En una época decían que yo era el culpable de la guerra, porque escribía sobre Malvinas para el diario La Capital de Rosario y frente a la Facultad estaba el Comando del Segundo Cuerpo, donde estaba Galtieri. Entonces me decían que Galtieri leía lo que yo decía en el diario y de ahí se le ocurrió lo de la guerra... ¡Por favor! ¡Lo único que me falta es que me echen la culpa de la guerra de Malvinas! (risas)

- ¿Quiénes piensa que han sido los principales exponentes de la disciplina en el país?

- Y... es complicado... Hoy en día yo diría (Carlos) Pérez Llana, (Roberto) Russell, (Juan) Tokatlián...

- ¿Y antes?

- Antes no había surgido otro nombre... Porque Russell empezó en la época de la democracia, Tokatlián durante la dictadura se tuvo que ir del país a Colombia, pero algunos de ellos no venían de las RI sino de la Sociología. Juan Carlos Puig, cuando se fue de la Argentina fundó en Caracas el Centro de Estudios Latinoamericanos. No hay muchos nombres más, iy no me quiero pelear con nadie!

- ¿Cuáles considera que son las disciplinas que más han influido en la disciplina de la RI? ¿En qué sentido lo han hecho?

- Yo creo que la relación más cercana de las RI es con el Derecho Internacional Público. Lo que sí hay mucho es un vínculo con la Sociología y la Sociología de las RI, que tuvo gran desarrollo en Francia. Algunos también hacen referencia a la Geopolítica. En Argentina cuando se habla de Geopolítica pareciera que uno habla de los militares, sin embargo, toda la estructura de Brasil está basada en la Geopolítica de (Mario) Travassos. Volviendo a los autores de RI, algo que me olvidé de mencionar es una gran experiencia que fue el RIAL (Programa de Relaciones Internacionales de América Latina). Ahí habría que hacer una lista de los académicos participantes de cada uno de los países, pero por ejemplo, en Chile podemos mencionar a (José Miguel) Inzulza, el Secretario General de la OEA; Luis Maira; Heraldo Muñoz, el actual Ministro de Relaciones Exteriores; Luciano Tomassini, quien fue el alma mater del RIAL. Al irse del país por Pinochet, toda esta gente que se fue principalmente a México, crearon allí un buen núcleo de RI.

- Cuando uno observa la tradición de las RI en los Estados Unidos es evidente una fuerte influencia de la Ciencia Política, pareciera que en el caso de Argentina en particular esto no fuera tan fuerte...

- En Rosario fue al revés, sobre todo por la tradición heredada que venía del Derecho Consular y el Derecho Diplomático. Una vez vino un profesor norteamericano y nos preguntaba, ¿por qué Rosario es tan fuerte en RI? Y le dijimos que era fundamentalmente porque era granero del mundo y precisaba expertos en comercio internacional y en el mundo, algo que sigue pasando hoy en día. Me parece que la tradición viene por ahí. Sin embargo, en la SAAP la influencia sí vino por Ciencia Política, en la AADI vino por el Derecho Internacional. Nosotros donde podíamos construir, estábamos.

- ¿Cuál considera que es el impacto que ha tenido el trabajo realizado en Rosario en los desarrollos teóricos y conceptuales posteriores de la disciplina?

- En el campo teórico todavía se tiene muy en cuenta la Teoría de la Autonomía de Juan Carlos Puig. Las teorías del sur, con la Teoría del Desarrollo de Prebisch, la Teoría de la 
Autonomía de Jaguaribe-Puig, esas son las principales líneas, ahora muchos se han ido hacia el constructivismo.

- ¿Cuáles son, a su entender, las particularidades que adquiere la disciplina en el país en relación a su historia?

- Yo creo que no la inventamos nosotros. En lo que a mí respecta yo me formé siguiendo la Escuela Francesa de Aaron y Hoffman. No teníamos una consistencia propia. Incluso en esa época, recuerdo que lo propuse a (Luis) Dallanegra (Pedraza) como relator en un Congreso de Derecho Internacional sobre Teoría de las RI, y yo decía, ¿vale la pena que hagamos teoría de las RI con todo el avance que hay en el mundo en teoría? Y nos convencimos de que sí. Teníamos que tener algunas teorías propias porque si no quedábamos presos de lo que se pensaba en el norte. De ahí que podamos mencionar algunos avances teóricos como la Autonomía de Puig y el Realismo Periférico.

— ¿Cuáles han sido los temas de agenda más analizados?

- Yo recuerdo que eran vastísimos. Inicialmente nos basábamos en la agenda de Naciones Unidas. Hoffman lo explica de una manera quizás un poco extrema: en RI es conflicto o es cooperación. La parte de conflicto para mí es la más interesante. Yo estudié la guerra entre Honduras y El Salvador, empecé con Nigeria para ver si me daba resultado una metodología propia que estaba probando que tiene cuatro pasos: toma en cuenta todos los actores internacionales (no sólo los Estados), el sistema internacional (porque no es lo mismo hacer una guerra en la Guerra Fría que en la pos-Guerra Fría), los objetivos perseguidos por cada uno de los actores y los medios (militares, diplomáticos, etc.). Es una metodología que está disponible en la página web del CERIR publicada en portugués y que se ha usado mucho en el ISEN cuando tienen que desarrollar un tema libre.

- ¿Cuáles han sido a su entender las principales instituciones que han contribuido al desarrollo de las RI en Argentina?

- Sobre algunas ya fuimos hablando, pero yo creo que la SAAP es importante porque surgió después del gobierno militar, en la época de Alfonsín, con gente amiga como Catterberg, Fontana, Strasser. La AADI, que todavía tiene la sede en Rosario, donde colaboramos mucho al principio con Puig para crearla.

- ¿Cree que el ISEN tuvo alguna incidencia en el desarrollo de la disciplina y las particularidades que fue adquiriendo?

- Fue importante para Rosario que nuestros graduados ingresaran al Servicio Exterior y que hoy estén distribuidos por el mundo en Consulados y Embajadas. También es importante el CARI, que en una época recibió subsidios de la Cancillería. Nosotros hemos hecho varias presentaciones de libros allí. Eso tal vez se podría haber aprovechado un poco más. El CONICET sí, yo creo que fue importante. Yo fui el primer académico de las RI en ser parte de la Junta, nos costó mucho trabajo construir la disciplina allí y muchos investigadores han hecho su carrera gracias al CONICET, con los distintos subsidios y becas. Guillermo Figari fue discípulo mío y tuvo beca del CONICET, y así muchos más.

- ¿El CONICET fue la principal fuente de financiamiento o tuvieron también financiamiento externo?

- El CONICET fue la principal fuente de financiamiento, pero hemos tratado de internacionalizarnos a partir de la participación en reuniones regionales y globales. En tanto director de los becarios, promoví que los investigadores que se especializaban en las distintas regiones o países tuvieran la oportunidad de visitarlos y participar en los debates. Miryam Colacrai que se especializaba en Antártida, fue como seis o siete veces; Gladys Lechini, recorrió todo el continente africano; Anabella Busso viajó varias veces a Estados Unidos... 
- ¿Cuál considera que es la influencia de corrientes internacionales de pensamiento en el desarrollo de la disciplina en la Argentina?

- Roberto Russell a través del Grupo Editor Latinoamericano estaba a cargo de publicar obras de autores norteamericanos para distribuirlos en América Latina, contribuyendo a promover el pensamiento norteamericano. Yo una vez le comenté a Russell que podría haber traducido a otros autores norteamericanos muy importantes, así como a franceses, ingleses e italianos que habían sido relegados. El problema es que hoy yo voy Colombia, voy a Brasil, voy a cualquier lado y cuando me entregan los trabajos de final de curso, en la bibliografía siempre figuran autores norteamericanos, y me da un poco de bronca. Claro, lo citan a Hoffman y Hoffman dice que las RI empezaron en Estados Unidos y eso es una mirada parcial. La influencia de Estados Unidos en América Latina marcó también la bibliografía que consumimos. Kaplan que tenía unos intentos por armar modelos de RI muy bueno no fue traducido. Tampoco (Alfred) Mahan que se ocupaba de la Geopolítica. Inzulza es uno de los mejores de América Latina escribiendo de Geopolítica y no era militar. 
Cuadernos de Política Exterior Argentina (Nueva Época), 126, julio-diciembre 2017, pp. 101-107 ISSN 0326-7806 (edición impresa) - ISSN 1852-7213 (edición en línea) 